\title{
PELAKSANAAN KONSEP DASAR K3 DALAM MELINDUNGI TENAGA MEDIS DI RUMAH SAKIT
}

\author{
Ade Herawati Sahputri \\ adehera92@gmail.com
}

\section{Latar Belakang}

Keselamatan dan kesehatan kerja merupakan hal penting yang harus diterapkan di semua tempat kerja, baik pada sektor formal maupun sektor informal. Terlebih bagi tempat kerja yang memiliki risiko atau bahaya yang tinggi, serta dapat menimbulkan kecelakaan kerja maupun penyakit akibat kerja. keselamatan dan kesehatan kerja seharusnya diterapkan pada semua pihak yang terlibat dalam proses kerja, mulai dari tingkat manager sampai dengan karyawan biasa. Berdasarkan Undang-Undang No. 1 Tahun 1970 yang menyatakan bahwa setiap tenaga kerja memiliki hak untuk mendapat perlindungan bagi keselamatannya dalam melakukan pekerjaan untuk kesejahteraan hidup dan meningkatkan produksi serta produktivitas Nasional.

Salah satu tempat kerja yang berisiko adalah Rumah Sakit, hal ini karena rumah sakit memiliki potensi terjadinya penyakit infeksi terhadap para karyawan, pasien, bahkan pengunjung. Beberapa contoh penyakit infeksi yang dapat terjadi di Rumah Sakit adalah TB, Hepatitis B,
Hepatitis C, dan bahkan berisiko terinfeksi HIV/AIDS. Selain penyakit-penyakit infeksi, di rumah sakit juga memiliki risiko atau bahaya lain yang mempengaruhi situasi dan kondisi di rumah sakit, seperti kecelakaan (meliputi kejadian ledakan, kebakaran, kecelakaan yang diakibatkan adanya masalah pada instalasi listrik, serta faktor-faktor yang dapat menimbulkan cidera lainnya), radiasi, paparan bahan kimia beracun dan berbahaya, gas-gas anastesi, gangguan terkait psikis dan ergonomi. Semua potensi bahaya tersebut di atas, jelas dapat mengganggu dan menimbulkan rasa kurang aman dan nyaman bagi pekerja di RS, pasien maupun pengunjung yang ada di lingkungan RS. (KEPMENKES N0.432 Tahun 2007).

Karyawan rumah sakit terdiri dari tenaga medis dan tenaga non medis. Tenaga medis yaitu dokter, perawat, dan bidan sedangkan tenaga non medis yaitu petugas laundry, petugas kebersihan, petugas penyiapan makanan atau gizi, apoteker, Pemeriksa laboratorium, dan petugas radiologi (Wichaksana, 2002). Dilihat dari jenis pekerjaan yang ada di rumah sakit, dapat 
dikatakan tenaga medis merupakan karyawan yang rentan terkena penyakit akibat kerja, karena mereka selalu melakukan kontak dengan pasien yang sakit setiap hari. Namun tenaga non medis juga memiliki potensi untuk terkena penyakit akibat kerja, walaupun mereka tidak melakukan kontak langsung dengan pasien. Berbagai penyakit infeksi menular kepada tenaga non medis melalui media udara, lantai, dinding, ruang kerja, jarum suntik bekas, dan infus bekas.

\section{Metode}

Metode yang digunakan dalam kajian ini adalah metode literature review yaitu metode dengan cara membaca dari berbagai sumber seperti jurnal online, skripsi, dan ebook serta membandingkan isi dari berbagai sumber yang dibaca dan menyimpulkan dalam hasil kajian yang didapatkan pada jurnal, skripsi, e-book mengenai konsep dasar kesehatan dan keselamatan kerja yang terbagi atas sehat, kesehatan kerja, risiko \&hazard dalam pemberian asuhan keperawatan.

\section{Hasil}

Kesehatan kerja merupakan suatu kondisi yang bebas dari gangguan secara fisik dan psikis yang disebabkan oleh lingkungan kerja. Risiko kesehatan dapat terjadi karena adanya faktor-faktor dalam lingkungan kerja yang bekerja melebihi periode waktu yang ditentukan dan lingkungan yang menimbulkan stress atau gangguan fisik. Risiko keselamatan dapat terjadi karena aspek-aspek dari lingkungan kerja yang dapat menyebabkan kebakaran, sengatan aliran listrik, terpotong, luka memar, keseleo, patah tulang, serta kerusakan anggota tubuh, penglihatan dan pendengaran.

Keselamatan kerja adalah keselamatan yang berhubungan dengan aktivitas kerja manusia baik pada industri manufaktur, yang melibatkan mesin, peralatan, penanganan material, pesawat uap, bejana bertekanan, alat kerja, bahan dan proses pengolahannya, landasan tempat kerja dan lingkungannya serta cara-cara melakukan pekerjaan, maupun industri jasa, yang melibatkan peralatan berteknologi canggih, seperti lift, eskalator, peralatan pembersih gedung, sarana transportasi, dan lain-lain.

Tujuan Kesehatan dan Keselamatan Kerja menurut Mangkunegara (2002) adalah agar setiap pegawai mendapat jaminan kesehatan dan keselamatan kerja baik secara fisik, sosial dan psikologis.agar setiap perlengkapan dan peralatan kerja digunakan sebaik - baiknya dan seektif mungkin, agar semua hasil produksi dipeliharan keamanannya, agar adanya jaminan atas pemeliharaan dan peningkatan kesehatan gizi pegawai. 
Proses Sistem Manajemen Kesehatan dan Keselamatan Kerja menurut H. M Yani ( 2012 ), pelaksanaan Kesehatan dan Keselamatan Kerja di perusahaan sangat tergantung dari rasa tanggung jawab manajemen dan tenaga kerja terhadap tugas dan kewajiban masing-masing serta kerjasama dalam pelaksanaan K3. Proses manajemen K3 meliputi pelaksanaan fungsi-fungsi manajemen di bidang K3 yaitu fungsi perencanaan, pelaksanaan dan pengawasan. Pelaksanaan program K3 sasarannya adalah tempat kerja yang aman dan sehat. Untuk itu semua permasalahan yang menghambat tercapainya tujuan harus diidentifikasi, dievaluasi, dicari penyebab dasarnya untuk kemudian diupayakan cara pemecahan yang paling baik.

Pogram keselamatan kerja menurut Mangkunegara ( 2000 ) Keselamatan Kerja menunjukan pada kondisi yang aman atau selamat dari penderitaan, kerusakan atau kerugian di tempat kerja. Keselamatan Kerja adalah keselamatan yang berkaitan dengan mesin, pesawat, alat kerja, bahan dan proses pengolahannya, landasan tempat kerja dan lingkungannya serta cara-cara melakukan pekerjaan.

\section{Pembahasan}

Berdasarkan Peraturan Menteri Kesehatan Republik Indonesia Nomor 66 Tahun 2016 tentang Keselamatan dan Kesehatan Kerja
Rumah Sakit bahwa keselamatan kerja adalah upaya yang dilakukan untuk mengurangi terjadinya kecelakaan, kerusakan dan segala bentuk kerugian baik terhadap manusia, maupun yang berhubungan dengan peralatan, obyek kerja, tempat bekerja, dan lingkungan kerja secara langsung dan tidak langsung.

\section{Kesehatan Kerja}

Kesehatan kerja merupakan suatu kondisi yang bebas dari gangguan secara fisik dan psikis yang disebabkan oleh lingkungan kerja. Risiko kesehatan dapat terjadi karena adanya faktor-faktor dalam lingkungan kerja yang bekerja melebihi periode waktu yang ditentukan dan lingkungan yang menimbulkan stress atau gangguan fisik. Risiko keselamatan dapat terjadi karena aspek-aspek dari lingkungan kerja yang dapat menyebabkan kebakaran, sengatan aliran listrik, terpotong, luka memar, keseleo, patah tulang, serta kerusakan anggota tubuh, penglihatan dan pendengaran. (Megginson dalam Mangkunegara,2000). Kesehatan kerja merupakan suatu kondisi yang bebas dari ganguan secara fisik dan psikis yang disebabkan oleh lingkungan kerja. Resiko kesehatan dapat terjadi karena adanya faktor-faktor dalam lingkungan kerja yang bekerja melebihi periode waktu yang ditentukan dan lingkungan yang 
menimbulkan stres atau gangguan fisik, $\mathrm{M}$ Yani ( 2012 ).

\section{Keselamatan Kerja}

Keselamatan kerja adalah keselamatan yang berhubungan dengan aktivitas kerja manusia baik pada industri manufaktur, yang melibatkan mesin, peralatan, penanganan material, pesawat uap, bejana bertekanan, alat kerja, bahan dan proses pengolahannya, landasan tempat kerja dan lingkungannya serta cara-cara melakukan pekerjaan, maupun industri jasa, yang melibatkan peralatan berteknologi canggih, seperti lift, eskalator, peralatan pembersih gedung, sarana transportasi, dan lain-lain.

Menurut Atika Puspita Sari ( 2012 ) Keselamatan kerja telah menjadi salah satu hak azasi manusia yang harus dilindungi oleh pemerintah dan dihargai oleh anggota masyarakat lainnya. Tenaga kerja harus memperoleh perlindungan dari berbagai soal di sekitarnya dan pada dirinya yang dapat menimpa atau mengganggu dirinya serta pelaksanaan pekerjaannya ( Mondy 2008 ).

Menurut WHO yang dikutip oleh Swarjana (2017), faktor-faktor yang menyebab terjadinya kecelakaan kerja dan penyakit akibat kerja adalah:

1. Faktor manusia Beberapa faktor yang menyebabkan manusia dapat menimbulkan kecelakaan kerja atau penyakit akibat kerja adalah umur, pengalaman, penggunaan obat, dan motivasi. Kecelakaan juga sering terjadi oleh karena tanggung jawab yang tidak baik, pengambilan keputusan yang tidak tepat, atau keputusan tepat tetapi aksinya terlalu lambat. Untuk menghindari itu manusia perlu melakukan observasi dan pengenalan terhadap bahaya.

2. Faktor lingkungan (fisik, kimiawi, biologis, fisiologis, psikologis) Penyebab kecelakaan kerja lainnya adalah faktor lingkungan pekerjaan misalnya pencahyaan, kebisingan, temperatur, debu, uap, gas, kesalahan konstruksi mesin, sikap badan yang tidak benar dalam melakukan pekerjaan, dan yang lainnya.

3. Faktor organisasi Kecelakaan kerja merupakan kejadian yang tidak diinginkan oleh siapa pun, terlebih pekerja itu sendiri. Setiap pekerja selalu menginginkan dapat bekerja dengan nyaman, aman tanpa ada rasa ketakutan akan terjadinya kecelakaan kerja. Oleh karena itu, lingkungan sosial atau organisasi memiliki efek paling besar terhadap kinerja seseorang

\section{Resiko}

Risiko adalah gabungan dari kemungkinan (frekuensi) dan akibat atau konsekuensi dari terjadinya bahaya tersebut. Penilaian risiko adalah penilaian menyeluruh untuk mengidentifikasi bahaya dan menentukan apakah risiko dapat diterima. Manajemen 
risiko adalah pengelolaan risiko yang mencakup identifikasi, penilaian, dan pengendalian risiko. Manajemen risiko terdiri dari 3 langkah pelaksanaan yaitu identifikasi bahaya, penilaian risiko dan pengendalian risiko (Ramli, 2010).

Penilaian risiko adalah proses untuk menentukan pengendalian terhadap tingkat risiko kecelakaan kerja/ penyakit akibat kerja. Penilaian risiko adalah proses evaluasi risiko-risiko yang diakibatkan adanya bahaya-bahaya, dengan memperhatikan kecukupan pengendalian yang dimiliki, dan menentukan apakah risikonya dapat diterima atau tidak

\section{Hazard}

Kurniawan (2008) mengatakan bahwa hazard adalah faktor faktor intrinsik yang melekat pada sesuatu berupa barang atau kondisi dan mempunyai potensi menimbulkan efek kesehatan maupun keselamatan pekerja serta lingkungan yang memberikan dampak buruk.

Hazard dapat diklasifikasikan menjadi 3 yaitu : a) bahaya biologis didefinisikan untuk dimasukkan luka/ luka/ laserasi, luka terkait yang tajam, kontak langsung dengan spesimen yang terkontaminasi/ bahan biohazardous, bioterorisme, yang ditularkan melalui darah patogen, penyakit infeksi/ infeksi, penyakit udara,penyakit vektor yang ditanggung, dan kontaminasi silang dari material kotor; b) bahaya nonbiologis didefinisikan untuk termasuk fisik, psikososial, dan ergonomis bahaya: bahaya fisik termasuk slip, perjalanan, jatuh, luka bakar, fraktur, radiasi dari sinar $\mathrm{X}$, kebisingan, dan radiasi nonionisasi bahaya fisik termasuk slip, perjalanan, jatuh, luka bakar, fraktur, radiasi dari sinar $\mathrm{X}$, kebisingan, dan radiasi nonionisasi; bahaya psikososial termasuk fisik, penyalahgunaan psikososial, seksual, dan verbal dan menekankan; bahaya ergonomis adalah muskuloskeletal cedera seperti nyeri otot/ strain/ terkilir.

Risiko dan Hazard dalam Pengkajian Asuhan Keperawatan

Seluruh kegiatan yang dilakukan baik yang dilakukan baik perseorangan ataupun organisasi atau bahkan perusahaan juga mengandung risiko. Semakin besar risiko yang dihadapi pada umumnya dapat diperhitungkan bahwa pengembalian yang diterima juga akan lebih besarL(Qoriawaty, 2016). Pola pengambilan risiko menunjukkan sikap yangberbeda terhadap pengambilan risiko. Menurut Prayitno, dkk (2017) risiko melekat dari tindakan pelayanan kesehatan dalam hal ini pada saat melakukan pengkajian asuhan keperawatan adalah bahwa dalam kegiatan ini yang diukur adalah upaya yang dilakukan. Pada proses pengkajian data, hal-hal yang dapat terjadi seperti : a). a) Kurangnya informasi 
atau data yang diberikan keluarga pasien/ .pasien tersebut (menyembunyikan sesuatu hal) sehingga dalam proses pengkajian kurang lengkap. Akibatnya perawat/dokter akan salah dalam memberikan perawatan sehingga berbahaya terhadap pasien b) Tertularnya penyakit saat melakukan pengkajian dalam hal ini seperti kontak fisik maupun udara. Pada saat perawat melakukan perawatan/pengkajian pasien maka perawat mempunyai resiko tertular penyakit dari pasien. c) Mendapatkan cacian atau pelecehan verbal saat melakukan pengkajian ataupun pada proses wawancara. Dalam hal ini seperti halnya ketika perawat menanyakan data/informasi pasien namun, keluarga/pasien menyembunyikannya namun demi keselamatan pasieen, perawat tetap menanyakannya sehingga pasien/keluarga pasien kurang menyukainya sehingga perawat mendapatkan cacian/perlakuan tidak baik. d) Mendapatkan kekerasan fisik dari pasien ataupun dari keluarga pasien pada saat melakukan pengkajian/pemeriksaan. Misalnya, Pasien/keluarga yang tidak menyukai proses perawatan/pengkajian dapat melakukan kekerasan fisik terhadap perawatnya

\section{Penutup}

Keselamatan Kerja adalah upaya yang dilakukan untuk mengurangi terjadinya kecelakaan, kerusakan dan segala bentuk kerugian baik terhadap manusia, maupun yang berhubungan dengan peralatan, obyek kerja, tempat bekerja, dan lingkungan kerja, secara langsung dan tidak langsung. Sedangkan kesehatan kerja adalah upaya peningkatan dan pemeliharaan derajat kesehatan yang setinggi-tingginya bagi pekerja di semua jabatan, pencegahan penyimpangan kesehatan yang disebabkan oleh kondisi pekerjaan, perlindungan pekerja dari risiko akibat faktor yang merugikan kesehatan, penempatan dan pemeliharaan pekerja dalam suatu lingkungan kerja yang mengadaptasi antara pekerjaan dengan manusia dan manusia dengan jabatannya.

\section{Daftar Pustaka}

Azizah, Nur dkk .2019. HUBUNGAN ANTARA PENGAWASAN, PROSEDUR KERJA DAN KONDISI FISIK DENGAN TERJADINYA KECELAKAAN KERJA PADA PERAWAT DI RUANG RAWAT INAP RUMAH SAKITPERMATA BUNDA MEDAN TAHUN 2017. JURNAL JUMANTIK. 3 (2). 125 - 134

Ernawati, Novi dkk. 2017. FAKTORFAKTOR YANG BERHUBUNGAN DENGAN PELAKSANAAN PENERAPAN K3 PADA TENAGA KESEHATANDI RSIA PERMATA 
SARANA HUSADA PERIODE FEBRUARI 2015. Jurnal Akademi Keperawatan Husada Karya Jaya, 3 (1). 12 - 18

Hasibuan, Rahman. 2017. PENGARUH KESEHATAN $D A N$ KESELAMATAN KERJA, PELATIHAN DAN KERJA TIM TERHADAP KINERJA TENAGA MEDIS DI RUMAH SAKIT BUDI KEMULIAAN BATAM. Jurnal DIMENSI. 6 (2). 323 - 328

HIDAYAH, WULAN FATWA . (2019) . ANALISIS FAKTOR RISIKO DAN HAZARD DALAM IMPLEMENTASI KEPERAWATAN. Bachelor thesis, UNIVERSITAS

MUHAMMADIYAH

PURWOKERTO.

Nazirah, Riska dan Yuswardi. 2017. PERILAKU PERAWAT DALAM PENERAPAN MANAJEMEN KESEHATAN $D A N$ KESELAMATAN KERJA (K3) DI $A C E H$. Idea Nursing Journal.8 (3).

Nurhidayanti, Deni. 2017. PENGARUH PELAKSANAAN KESELAMATAN DAN KESEHATAN KERJA (K3) TERHADAP KEPUASAN KERJA PERAWAT (Studi Kasus Rumah Sakit Umum Daerah (RSUD)Arifin
Achmad Pekanbaru). JOM FISIP. 4 (1) . $1-10$

SEMBIRING, SISILIA FEAGITHA. 2018. “ Penerapan Keselamatan dan Kesehatan Kerja di Rumah Sakit Umum Daerah Kabanjahe Kabupaten Karo Sumatera Utara “. Skripsi. FAKULTAS KESEHATAN MASYARAKAT. ILMU KESEHATAN MASYARAKAT. UNIVERSITAS SUMATERA UTARA. Medan

Simamora, R. H. (2011). ROLE CONFLICT OF NURSE RELATIONSHIP WITH PERFORMANCE IN THE EMERGENCY UNIT OF HOSPITALS RSD DR. SOEBANDI JEMBER. The Malaysian Journal of Nursing, 3(2), 23-32.

Sri Rejeki. 2016. KESEHATAN DAN KESELAMATAN KERJA. KEMENTERIAN KESEHATAN REPUBLIK INDONESIA : Jakarta Yuantari dkk .2018. Analisis Risiko Keselamatan dan Kesehatan Kerja Pada Petugas Kebersihan di Rumah Sakit.Faletehan Health Journal. 5 (3) . 107-116

Yuttya, Triesda .2018. MANAJEMEN RISIKO K3 MENGGUNAKAN HAZARD IDENTIFICATION RISK 
ASSESSMENT AND RISK

CONTROL (HIRARC). JURNAL

KESEHATAN. 9 ( 1 ). 39 - 52 